\title{
VIRULENSI BEBERAPA ISOLAT METARHIZIUM ANISOPLIAE TERHADAP ULAT GRAYAK (Spodoptera litura F.) di LABORATORIUM
}

\author{
Ketut Aryo, Purnomo, Lestari Wibowo \& Titik Nur Aeny \\ Jurusan Agroteknologi, Fakultas Pertanian Universitas Lampung \\ Jl. Soemantri Bojonegoro No. 1 Bandar Lampung 35145 \\ Email: ketutaryo@gmail.com
}

\begin{abstract}
ABSTRAK
Penelitian ini bertujuan untuk mempelajari pertumbuhan koloni, viabilitas spora serta kerapatan spora dari lima isolat Metarhizium anisopliae dan mempelajari pengaruh aplikasi Metarhizium anisopliae terhadap mortalitas Spodoptera litura F. Penelitian ini dilaksanakan di Laboratorium Hama Tumbuhan dan Laboratorium Penyakit Tumbuhan, Bidang Proteksi Tanaman Jurusan Agroteknologi, Fakultas Pertanian Universitas Lampung pada akhir tahun 2013 (Tahap I) dan dilanjutkan pada awal tahun 2016 (Tahap II). Hasil Penelitian menunjukkan bahwa : Tidak terdapat perbedaan viabilitas spora M. anisopliae yang nyata antar 5 isolat asal Tegineneng, Trimurjo, Gadingrejo, Bantul dan UGM; Kerapatan isolat asal UGM adalah 2,25 x 109 $\mathrm{spora} / \mathrm{ml}$, lebih tinggi dibandingkan dengan isolat asal Gadingrejo, Bantul, Tegineneng dan Trimurjo; Isolat M. anisopliae asal UGM mampu membunuh ulat grayak ( $S$. litura) hingga 86,67\%, isolat lain memiliki kemampuan lebih rendah dibandingkan isolat asal UGM.
\end{abstract}

Kata kunci: diameter koloni, kerapatan spora, viabilitas spora, virulensi, Metarhizium anisopliae, ulat grayak (Spodoptera litura F.).

\section{PENDAHULUAN}

Ulat grayak (Spodoptera litura Fabr. )merupakan salah satu hama penting pada tanaman kedelai. S. litura dapat hidup pada berbagai jenis tanaman, seperti tembakau, kacang tanah, ubi jalar, cabai, bawang merah, kacang hijau, dan jagung. Ulat instar muda merusak daun sehingga bagian daun yang tersisa hanya tulang-tulang daun, dan ulat instar tua memakan seluruh bagian daun. Selain merusak daun, larva juga menyerang polong muda (Prayogo et al., 2005).

Pengendalian ulat grayak pada saat ini masih mengandalkan penggunaan insektisida. Pengendalian menggunakan insektisida kimia diketahui memiliki dampak buruk untuk kedepannya, selain merusak dan meracuni tanah insektisida kimia dapat mematikan serangga lain di sekitar area pertanaman yang bukan merupakan suatu hama. Untuk mendukung pengendalian hama yang berwawasan lingkungan maka perlu dilakukannya pengendalian yang ramah lingkungan, Purnomo (2010) berpendapat salah satu tawaran alternatif teknik pengendalian yang ramah lingkungan yaitu pengendalian hayati, yang lebih fokus pada penggunaan musuh alami hama, atau agens pengendali hayati. Pengendalian hayati menggunakan parasitoid, predator, patogen, atau kompetitor yang dapat menekan populasi hama, sehingga menurunkan tingkat kerusakan bila dibandingkan jika musuh alami tidak ada. Salah satu jenis patogen serangga adalah jamur entomopatogenik.

Pemanfaatan jamur entomopatogen berpotensi untuk dikembangkan. Salah satu jenis jamur entomopatogen yang cukup efektif adalah Metarhizium spp. Salah satu cendawan Metarhizium spp. yang seringdigunakan dan merupakan bagian dari fokus penelitian ini adalah Metarhizium anisopliae.

Penelitian ini bertujuan untuk mengetahui pertumbuhan koloni, viabilitas spora, serta kerapatan spora dari lima isolat $M$. anisopliae. Mengetahui hubungan antara pertumbuhan koloni, viabilitas spora, dan kerapatan spora $M$. anisopliae dengan mortalitas S. litura. Mengetahui virulensi Metarhizium anisopliae terhadap S. litura.

\section{BAHAN DAN METODE}

Penelitian ini dilaksanakan di Laboratorium Hama Tumbuhan dan Laboratorium Penyakit Tumbuhan, Bidang Proteksi Tanaman Jurusan Agroteknologi, Fakultas Pertanian Universitas Lampung pada akhir tahun 2013 (Tahap I) dan dilanjutkan pada awal tahun 2016 (Tahap II).

Bahan-bahan yang diperlukan dalam penelitian ini adalah serangga ulat grayak (S. litura), tanaman padi, media SDA (sabouraud dextrose agar), tissu, alkohol 
$70 \%$, kapas, aqua destilata steril, isolat M. anisopliae dari Tegineneng, Gading Rejo, Bantul, UGM, dan Trimurjo. Sedangkan alat-alat yang dibutuhkan yaitu toples plastik, plastik tahan panas, kain kasa, tabung pemelihara serangga, nampan plastik, cawan petri, haemocytometer, erlenmeyer, rotamixer, jarum ose, bor gabus, mikropippet, laminar air flow, mikroskop, preparat, kaca penutup, autoclave, dan tabung reaksi.

Penelitian ini berupa percobaan dalam rancangan acak kelompok (RAK) yang dibagi dalam 2 bagian. Pertama pengukuran pertumbuhan koloni cendawan, pengamatan kerapatan spora, dan viabilitas spora. Pengukuran pertumbuhan koloni cendawan terdiri dari 5 perlakuan dan 4 kelompok, pengamatan kerapatan spora dan viabilitas spora terdiri dari 5 perlakuan dan 3 kelompok, dan kedua uji virulensi terdiri dari 6 perlakuan dan 3 kelompok. Pengamatan pertumbuhan koloni cendawan sebagai perlakuan adalah 5 isolat $M$. anisopliae (Tegineneng, Gading Rejo, UGM, Bantul, dan Trimurjo), kelompok bedasarkan berapa kali dilakukan pengukuran. Pengamatan kerapatan spora dan viabilitas spora sebagai perlakuan adalah 5 isolat M. anisopliae (Tegineneng, Gading Rejo, UGM, Bantul, dan Trimurjo), kelompok berdasarkan waktu pengamatan. Pengujian virulensi sebagai perlakuan adalah 5 isolat M. anisopliae (Tegineneng, Gading Rejo, UGM, Bantul, dan Trimurjo) dan 1 kontrol, kelompok berdasarkan waktu aplikasi yang berbeda.

Penyiapan Serangga Spodoptera litura F. Pembiakan serangga ulat grayak dilakukan di laboratorium. Serangga diperoleh dari penangkapan di lapang pada area pertanaman sayuran dan jagung manis. 10 ekor serangga kisaran instar 4-5 dimasukkan ke dalam toples plastik berukuran diameter $15 \mathrm{~cm} \times$ tinggi $7 \mathrm{~cm}$ yang berisi daun talas muda yang telah dipotong sebagai sumber makanan.

Pengukuran Diameter Koloni Cendawan Metarhizium anisopliae. Isolat cendawan diambil menggunakan bor gabus dan ditumbuhkan pada bagian tengah media SDA. Setelah itu cendawan diinkubasi untuk melihat pertumbuhannya dengan diukur diameter koloninya. Pengukuran dilakukan pada 4 cawan isolat di hari ke-3, ke-5, dan ke-7 setelah inokulasi. Pengamatan dilakukan terhadap diameter koloni cendawan yang tumbuh dari tiap-tiap jenis cendawan Metarhizium sp. Data diameter yang didapat merupakan nilai rata-rata 4 kali pengukuran diameter koloni cendawan yang tumbuh pada setiap sisinya.

Pengujian Kerapatan konidia M. anisopliae. Biakan cendawan Metarhizium sp. pada masing-masing media diambil sebanyak 1 potongan bor gabus lalu ditambahkan ke dalam air steril dalam tabung reaksi steril berukuran $10 \mathrm{ml}$ dan dikocok dengan shaker hingga tercampur merata ( \pm 10 menit). Selanjutnya dilakukan pengenceran hingga $10^{-3}$. Kerapatan spora dihitung dengan menggunakan alat hemasitometer di bawah mikroskop binokuler dengan perbesaran 400 kali. Kerapatan spora dihitung dengan menggunakan rumus Gabriel \& Riyatno (1989) sebagai berikut:

$$
\mathrm{C}=\frac{\mathrm{t} \times \mathrm{d}}{\mathrm{n} \times 0,25} \times 10^{6}
$$

Keterangan:

$\mathrm{C}=$ kerapatan spora per ml larutan

$\mathrm{t}=$ jumlah total spora dalam kotak yang diamati

$\mathrm{d}=$ tingkat pengenceran

$\mathrm{n}=$ jumlah $\operatorname{kotak}(5 \operatorname{kotak}$ besar $\mathrm{x} 16$ kotak kecil $)$

Pengujian viabilitas Metarhizium anisopliae. Viabilitas spora cendawan Metarhizium spp. ditentukan setelah suspensi spora diinkubasikan selama $24 \mathrm{jam}$. Satu tetes suspensi tersebut diteteskan pada kaca preparat dan ditutup dengan gelas penutup dan diletakkan di bawah mikroskop dengan perbesaran 400 kali. Selanjutnya dihitung jumlah spora yang berkecambah dan tidak berkecambah pada luasan bidang pandang yang telah ditentukan. Penghitungan viabilitas spora dilakukan setiap 2 jam sekali mulai sejak 12 jam sampai dengan 24 jam setelah inkubasi. Viabilitas spora dihitung dengan menggunakan rumus Gabriel \& Riyatno (1989) sebagai berikut :

$$
\mathrm{V}=\frac{\mathrm{g}}{(\mathrm{g}+\mathrm{u})} \times 100 \%
$$

Keterangan:

$\mathrm{V}=$ persentase konidia yang berkecambah

$\mathrm{g}=$ rata-rata konidia yang berkecambah

$\mathrm{u}=$ rata-rata konidia yang tidak berkecambah

Pengujian Virulensi Entomopatogen. Spora yang diambil dari media diencerkan dengan air steril sampai $10^{-3} / \mathrm{ml}$, kemudian disemprotkan pada 10 ekor ulat $S$. litura instar 5. Serangga hama kemudian dipindahkan ke tempat pemeliharaan yang dibuat dari toples plastikl dan diberi makan berupa daun talas. Pengamatan serangga yang mati dilakukan pada 3, 7, dan 10 hari setelah aplikasi (HSA). Menurut Rustama et al. (2008) bahwa mortalitas serangga dapat dihitung menggunakan rumus seperti berikut :

$$
\mathrm{M}=\frac{\sum \mathrm{n}}{\sum \mathrm{N}} \times 100 \%
$$


Keterangan:

$\mathrm{M}=$ mortalitas serangga ( $\%)$

$\mathrm{n}=$ serangga yang mati (ekor)

$\mathrm{N}=$ jumlah serangga yang diuji (ekor)

\section{HASIL DAN PEMBAHASAN}

Hasil Pengujian Pertumbuhan Koloni Cendawan. Hasil analisis ragam menunjukkan bahwa diameter koloni cendawan menunjukkan perbedaan ukuran diameter pada setiap pengamatan. Pertumbuhan $M$. anisopliae dari UGM pada 3 hari setelah inkubasi (hsi) menunjukkan pertumbuhan koloni yang paling tinggi dibandingkan dengan isolat lainnya dengan rata-rata diameter mencapai $2,80 \mathrm{~cm}$. Kemudian pada 5 hari setelah inkubasi (hsi) isolat Gadingrejo menunjukkan tingkat pertumbuhan tertinggi yaitu mencapai $7,80 \mathrm{~cm}$ dan pada 7 hari setelah inkubasi (hsi) dengan hasil ratarata diameter mencapai $8,63 \mathrm{~cm}$. Isolat Gadingrejo menunjukkan hasil yang paling tinggi tingkat pertumbuhannya (Tabel 1).
Hasil Pengujian Tingkat Kerapatan Spora. Hasil penelitian terhadap pengujian kerapatan spora $M$. anisopliae menunjukkan hasil yang berbeda nyata antara masing-masing perlakuan (Tabel 2). Dari Tabel 2 terlihat bahwa kerapatan spora yang memiliki tingkat kerapatan tertinggi adalah isolat yang berasal dari UGM dengan hasil rata-rata $2,25 \times 10^{9} \mathrm{spora} / \mathrm{ml}$ lebih tinggi dibandingkan dengan isolat asal Trimurjo dengan hasil rata-rata $2,09 \times 10^{9} \mathrm{spora} / \mathrm{ml}$

Hasil Pengujian Viabilitas Spora. Hasil penelitian terhadap pengujian viabilitas spora $M$. anisopliae menunjukkan hasil yang tidak berbeda nyata antara masing-masing perlakuan (Tabel 3). Viabilitas spora yang memiliki tingkat perkecambahan tertinggi berdasarkan rata - rata adalah isolat yang berasal dari UGM dengan hasil 76,88\% kemudian diikuti dari isolat yang berasal dari Gadingrejo 55,19\%, Tegineneng dengan hasil 45,27 $\%$, diikuti Bantul 41,86\%, dan Trimurjo 32,50\%.

Hasil Pengujian Virulensi M. Anisopliae. Pengujian virulensi isolat $M$. anisopliae memiliki hasil mortalitas yang beragam, dan menghasilkan hasil yang nyata antar perlakuan setelah dilakukan analisis statistik.

Tabel 1. Rata-rata diameter pertumbuhan koloni cendawan M. anisopliae

\begin{tabular}{cccc}
\hline \multirow{2}{*}{ Asal Isolat } & \multicolumn{3}{c}{ Diameter Koloni Cendawan M. anisopliae $(\mathrm{cm})$} \\
\cline { 2 - 4 } & $3 \mathrm{hsi}$ & $5 \mathrm{hsi}$ & $7 \mathrm{hsi}$ \\
\hline Trimurjo & $1,71 \mathrm{bc}$ & $5,03 \mathrm{bc}$ & $8,11 \mathrm{ab}$ \\
Gadingrejo & $1,90 \mathrm{bc}$ & $7,98 \mathrm{a}$ & $8,63 \mathrm{a}$ \\
Bantul & $2,30 \mathrm{ab}$ & $5,10 \mathrm{bc}$ & $6,49 \mathrm{bc}$ \\
Tegineneng & $1,14 \mathrm{c}$ & $3,66 \mathrm{c}$ & $5,34 \mathrm{c}$ \\
UGM & $2,80 \mathrm{a}$ & $6,97 \mathrm{ab}$ & $7,47 \mathrm{ab}$ \\
Nilai BNT & 0,77 & 2,42 & 1,73
\end{tabular}

Keterangan: hsi = hari setelah inokulasi, Nilai tengah yang diikuti huruf yang beda berbeda nyata menurut uji BNT pada taraf $(5 \%)$.

Tabel 2. Rerata Kerapatan spora Metarhizium anisopliae

\begin{tabular}{lc}
\hline \multicolumn{1}{c}{ Asal Isolat } & Rerata Kerapatan Spora (Spora/ml) \\
\hline UGM & $2,25 \times 10^{9} \mathrm{a}$ \\
Trimurjo & $2,09 \times 10^{9} \mathrm{~b}$ \\
Bantul & $2,01 \times 10^{9} \mathrm{bc}$ \\
Tegineneng & $1,75 \times 10^{9} \mathrm{c}$ \\
Gadingrejo & $1,68 \times 10^{9} \mathrm{c}$ \\
\hline Nilai & BNT: 0,13 \\
\hline
\end{tabular}

Keterangan: Pengujian tingkat kerapatan spora $M$. anisopliae yang diikut huruf yang sama berbeda nyata menurut uji BNT pada taraf $(5 \%)$. 


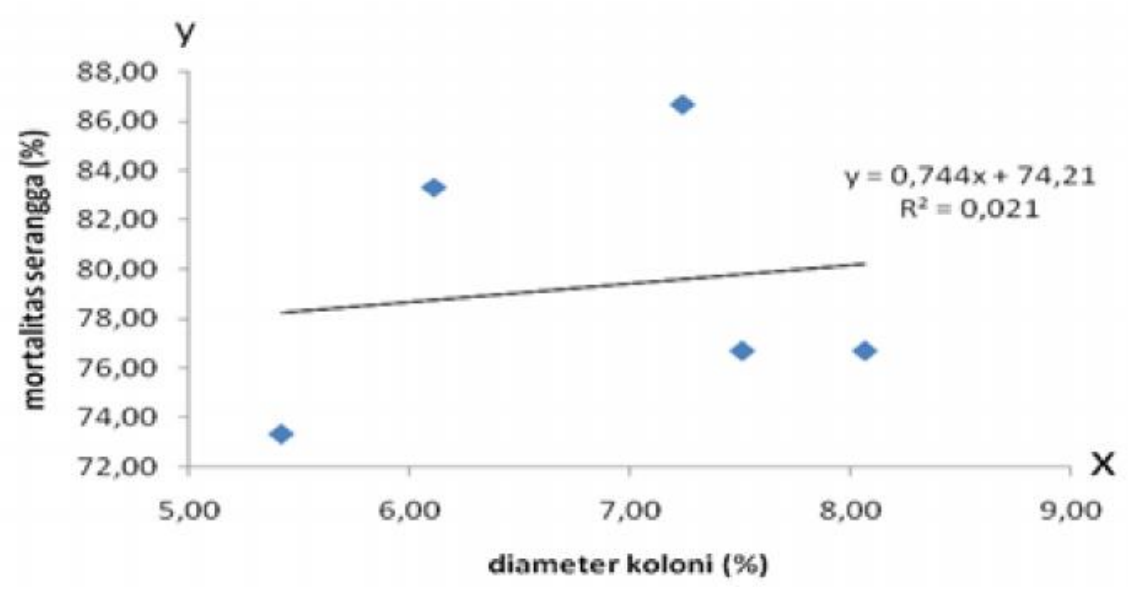

Gambar 1. Grafik regresi antara diameter koloni dan mortalitas serangga S. litura

Berdasarkan rata-rata persentase mortalitas serangga, isolat yang memiliki tingkat virulensi yang relatif lebih tinggi dari yang lainnya adalah isolat dari UGM dengan hasil mencapai 8,67\% serangga mati (Tabel 4) yang terinfeksi cendawan $M$. anisopliae.

Pada pengujian virulensi beberapa isolat $M$. anisopliae setelah 10 hari penginfeksian menghasilkan mortalitas $S$. litura tertinggi dengan nilai mencapai 86,67 $\%$ serangga mati, yaitu terdapat pada isolat asal UGM, kemudian diikuti isolat dari Bantul dengan nilai 83,33\% dan isolat asal Gadingrejo dan Trimurjo dengan nilai 76,67 $\%$ serangga mati dan nilai terendah isolat asal Tegineneng dengan nilai 73,33\%. Dalam aplikasi terhadap S. litura pada penelitian ini, suspensi $M$. anisopliae menggunakan pengenceran yang sama yaitu $10^{-3} / \mathrm{ml}$ setiap perlakuan dan aplikasi dilakukan hanya satu kali. Pada pengujian virulensi isolat $M$. anisopliae memiliki hasil mortalitas yang beragam, dan menghasilkan hasil yang nyata antar perlakuan setelah dilakukan analisis statistik pada uji BNT dengan taraf nyata $5 \%$.

Penelitian Prayogo dan Tengkano (2004) yang menyatakan bahwa mortalitas $S$. litura sangat ditentukan oleh frekuensi aplikasi $M$. anisopliae. Aplikasi M. anisopliae satu kali sebenarnya sudah mampu mematikan S. litura hingga 40\%. Begitupun hasil penelitian Suhairiyah (2013) yang menguji mortalitas $S$. litura pada agensia hayati cendawan Lecanicillium lecanii yang menunjukan kematian $S$. litura sebesar $83 \%$. Hal ini mungkin dipengaruhi oleh kerapatan konidia yang tinggi, maka semakin banyak juga miselium dan konidia yang tumbuh. Hal tersebut meningkatkan terjadinya kontak konidia dengan tubuh larva, sehingga memberi peluang yang lebih baik bagi konidia untuk menempel, berkecambah dan melakukan penetrasi ke dalam tubuh larva (Destiyanti, 2007)

Tingkat virulensi cendawan $M$. anisopliae tidak dipengaruhi oleh tingkat pertumbuhan diameter koloni cendawan, viabilitas spora cendawan dan kerapatan spora cendawan. Dari grafik regresi (Gambar 1) pengukuran diameter koloni cendawan $M$. anisopliae dari Gadingrejo memiliki tingkat pertumbuhan tertinggi yaitu $8,07 \mathrm{~cm}$ namun memiliki persentase mortalitas $S$. litura hanya $76,67 \%$. Di sisi lain isolat asal Tegineneng memiliki nilai pertumbuhan koloni terkecil yaitu sebesar $5,42 \mathrm{~cm}$ juga memiliki mortalitas $S$. litura dengan angka persentase terkecil yaitu $73,33 \%$.

Pada grafik regresi viabilitas spora dengan mortalitas (Gambar 3) didapatkan hasil yang tidak berbeda nyata antara viabilitas dengan mortalitas. Hal ini terjadi karena mungkin penambahan bahan pembawa yaitu media SDA menyebabkan viabilitas konidia M. anisopliae dapat bertahan.

Pada grafik regresi kerapatan spora dengan mortalitas (Gambar 2) menunjukkan hasil yang tidak berbeda nyata. Hal ini dikarenakan pada pengamatan kerapatan spora tidak menggunakan bahan pembawa. Menurut Effendy (2010) bioinsektisida tanpa bahan pembawa kerapatan konidianya $8,3 \times 10^{6}$ konidia/ $\mathrm{ml}$ berbeda nyata dengan bioinsektisida yang menggunakan bahan pembawa. Hal ini dapat disebabkan bahan pembawa bioinsektisida waktu pengenceran yang diambil $5 \mathrm{~g}$ bersama bahan pembawa, sedangkan konidia tanpa bahan pembawa diambil $5 \mathrm{~g}$ hanya konidia saja. Hal ini akan mengakibatkan jumlah konidia dalam suspensi memang sudah berbeda, tentunya konidia tanpa bahan pembawa akan lebih banyak. Hal ini mungkin yang menyebabkan pada isolat UGM walau memiliki 
nilai kerapan yang tinggi yaitu sebesar $2,25 \times 10^{9}$ spora/ $\mathrm{ml}$ dan nilai mortalitas yang tinggi sebesar $86,67 \%$ hal ini membuktikan ternyata nilai kerapatan yang tinggi bukan satu-satunya faktor yang menyebabkan terjadinya mortalitas. Hal ini didukung dengan pendapat Prayogo (2005) yang menyatakan selain toksin, faktor lingkungan juga berpengaruh terhadap mortalitas ulat grayak, yaitu seperti kelembaban dan suhu. Pada tahap penginfeksian cendawan terhadap serangga sasaran, kelembaban yang tinggi diperlukan untuk perkecambahn propagul cendawan.

Dalam pengujian pertumbuhan koloni cendawan dan viabilitas spora, menggunakan media yang berbeda dengan pengujian virulensi, yaitu media SDA (Sabouraud Dextrose Agar). Media SDA merupakan salah satu media yang digunakan untuk pertumbuhan cendawan yang sengaja dibuat untuk memiliki kandungan nutrisi untuk mensuplai makanan terhadap cendawan. Komposisi dari media SDA yang digunakan adalah $40 \mathrm{~g}$ Dextrose, $5 \mathrm{~g}$ Pepton, $5 \mathrm{~g}$ kasein, $15 \mathrm{~g}$ agar dan 1 liter air destilata. Glukosa merupakan salah satu jenis monosakarida yang menjadi sumber energi dan media pertumbuhan cendawan dalam sistem metabolisme. Monosakarida merupakan gula sederhana penyusun karbohidrat yang tidak dapat diuraikan secara hidrolisis. Bentuk alami (D-glukosa) dapat disebut juga dengan dekstrosa. Glukosa berperan sebagai sumber karbon bagi cendawan Candida albicans (Lestari, 2012 dalam Wayan et al., 2014). Sedangkan pengujian virulensi menggunakan media serangga $S$. litura yang berarti akan berbeda nutrisi yang akan diserap bahkan bisa jadi nutrisi yang tekandung dalam serangga uji terbatas sehingga menyebabkan hasil yang tidak sesuai.

Berdasarkan rata-rata persentase mortalitas serangga, isolat yang memiliki tingkat virulensi yang relatif lebih tinggi dari yang lainnya adalah isolat dari UGM dengan hasil mencapai $86,67 \%$ serangga mati (Tabel 4). Isolat M. anisopliae asal UGM relatif lebih baik berdasarkan perhitungan rata-rata untuk digunakan sebagai agens pengendali hayati hama S. litura. Pada umumnya virulensi yang tinggi disebabkan oleh toksin yang terkandung dalam cendawan. Isolat $M$. anisopliae asal UGM memiliki toksisitas yang tinggi untuk mematikan serangga $S$. litura sehingga mortalitasnya besar. Artinya dalam penelitian ini toksisitas dari masing-masing asal isolat $M$. anisopliae berbeda.

\section{KESIMPULAN}

Kesimpulan yang dapat diambil pada penelitian ini yaitu tidak terdapat perbedaan yang nyata pada viabilitas spora 5 isolat $M$. anisopliae (Tegineneng, Trimurjo, Gadingrejo, Bantul dan UGM ). Tingkat kerapatan spora tertinggi terdapat pada isolat asal UGM $\left(2,25 \times 10^{9} \mathrm{spora} / \mathrm{ml}\right)$. Virulensi M. anisopliae terhadap ulat grayak ( $S$. litura) tidak dipengaruhi oleh pertumbuhan koloni,viabilitas spora, dan kerapatan spora M. anisopliae. Isi isolat M. anisopliae asal UGM terhadap ulat grayak (S. litura ) mencapai $86,67 \%$, paling tinggi dibandingkam dengan isolat-isolat lainnya.

\section{DAFTAR PUSTAKA}

Desyanti. 2007. Kajian Pengendalian Rayap Tanah Coptotermes spp. (Isoptera: Rhinotermitidae) dengan Menggunakan Cendawan Entomopatogen Isolat Lokal. Skripsi. Institut Pertanian Bogor. Bogor. 97 hlm.

Effendy, Siti H., Chandra I., Salim A. dan Erni. 2010. Seleksi Substrat Jamur Metarhizium Sp. Untuk Mengendalikan Wereng Coklat Nilaparvata lugens (Stal.) (Homoptera: Delphacidae) Di Tanaman Padi. Majalah ilmiah Sriwijaya. 16(8).

Gabriel, BP dan Riyatno. 1989. Metarhizium anisopliae (Metch) Sor: Taksonomi,Patologi, Produksi dan Aplikasinya. Jakarta: Direktorat Perlindungan Tanaman Perkebunan, Departemen Pertanian. 
Prayogo, Y., Tengkano W., dan Marwoto. 2005. Prospek Cendawan Entomopatogen Metarhizium anisopliae Untuk Mengendalikan Ulat Grayak Spodoptera litura Pada Kedelai. J. Litbang Pertanian. 24(1): 19-26.

Purnomo, H. 2010. Pengantar Pengendalian Hayati. C.V Andi Offset. Yogyakarta.

Rustama, M. M., Melanie., dan Irawan B. 2008. Patogenisitas Jamur Entomopatogen Metarhizium anisopliae Terhadap Crocidolomia pavonana Fab. Dalam Kegiatan Studi Pengendalian Hama Terpadu Tanaman Kubis Dengan Menggunakan
Agensia Hayati. Laporan Penelitian. Universitas Padjadjaran. Jawa Barat. Diakses tanggal 14 Juli 2013.

Suhairiyah. 2013. Pengaruh Pemberian Cendawan Lecanicillium lecanii Terhadap Mortalitas Ulat Grayak (Spodoptera litura) Secara In Vitro. lentera bio 2 (3): 253-257.

Wayan, I. G., Ida B. R. W., dan Luh A. W. 2014. Pengaruh Penambahan Glukosa Dan Waktu Inkubasi Pada Media SDA (Sabaroud Dextrose Agar) Terhadap Pertumbuhan Jamur Candida albicans. Media Bina Ilmiah 8 (1): 51-56. 